\title{
THE EFFECT OF SURFACE PRE-TREATMENT OF AISI 321 STEEL IN FLOWING LEAD
}

\author{
Lukáš KOŠEK, Lucia ROZUMOVÁ, Anna HOJNÁ \\ Research Centre Rez, Husinec-Rez, Czech Republic, EU \\ lucia.rozumova@cvrez.cz, lukas.kosek@cvrez.cz
}

https://doi.org/10.37904/metal.2019.846

\begin{abstract}
One of the main concern in the development of the Gen IV lead-cooled fast reactors (LFRs) is the compatibility of the candidate structural steels and cladding materials with the heavy liquid metal (HLM). Structural materials compatibility in conditions relevant to plant operation is of primary importance to safety. The work describes performance of austenitic stainless steel AISI 321 with various surface pre-treatment exposed to liquid lead. The cylindrical specimens were pre-treated by using electro-polishing, pre-oxidation, and their combination as well as non-treated ones. Pre-oxidation was performed in argon with $30-50 \mathrm{~Pa} \mathrm{O}_{2}$ at $450-500{ }^{\circ} \mathrm{C}$ for 14 days. Then the specimens were exposed to lead at $480{ }^{\circ} \mathrm{C}$, flow velocity $\sim 3 \mathrm{~m} / \mathrm{s}$ and oxygen concentration $10^{-7} \mathrm{wt}$. $\%$ in corrosion loop MatLoo for $500 \mathrm{hr}$. The concentration of dissolved oxygen in liquid lead was controlled by mass exchange between flowing metal and argon cover gas with variable $\mathrm{Ar} \div 5 \% \mathrm{H}_{2}$ - $\mathrm{Ar}$ or $10 \% \mathrm{O}_{2}$-Ar ratio. Oxygen concentration was continuously monitored using electrochemical oxygen sensors with $\mathrm{Bi} / \mathrm{Bi}_{2} \mathrm{O}_{3}$ reference electrode. The Scanning Electron Microscope (SEM) with Energy Dispersive Spectroscopy (EDS) was used for post-test examination of the surfaces and cross sections of the specimens. The SEM observation demonstrated significant differences in the behaviour and in the formation of thin oxide layers of the specimens. From tested specimens the best performance showed that specimen in as-received condition while preoxidized specimen formed non homogeneous and non-protective oxide layer and electro-polished specimen showed vulnerability to intergranular corrosion attack.
\end{abstract}

Keywords: Loop MatLoo, AISI 321, forced circulation, lead coolant, corrosion

\section{INTRODUCTION}

Heavy liquid metals (HLMs) such as lead-bismuth eutectic (LBE) and lead are promising heat-transfer media, considered as a coolant for nuclear reactors. The application of HLM as a coolants promises the reduction of the costs over the sodium technology while maintaining its benefits: high boiling point (low pressure coolant), excellent heat transfer properties, decay heat removal by natural convection, intermediate neutron spectrum for better $U$ resources utilization, low reactivity with water, low pressure drop and high gamma shielding. On the other hand the HLM coolants have high freezing point, irradiated LBE is source of radiotoxic Po-210 isotope and are corrosive [1,2]. The compatibility with construction materials is one of the main drawbacks of HLM technology. The heavy metals have ability to selectively dissolve and mass transport soluble alloying elements from austenitic steels (like $\mathrm{Ni}$ and $\mathrm{Cr}$ ). The mitigation strategy for moderate operating temperatures $(<450-480$ ${ }^{\circ} \mathrm{C}$ ) is based on active oxygen control where the precise amount of oxygen leads to the formation of protective layers of $\mathrm{Fe}-\mathrm{Cr}$ and $\mathrm{Fe}_{3} \mathrm{O}_{4}$.oxides. The upper limit of oxygen concentration is limited by its solubility in the coolant and lower limit by thermodynamic stability of particular oxide [3,4]. The failure in coolant chemistry control has serious consequences for nuclear systems e.g., the accumulation of lead oxides blocked the coolant entrance into the core resulting in core meltdown on infamous Soviet submarine K-27 [5]. The extremely low oxygen concentrations with high temperatures can lead to dangerous localized corrosion with typical corrosion speed $2.5 \mathrm{~mm} / \mathrm{y}$ [6]. The fuel cladding wall thickness $0.5 \mathrm{~mm}$ is used in liquid metal cooled reactors and expected core lifetime is from $5-30$ y depending on application $[7,8]$. Therefore, the interaction of construction materials with flowing heavy metal is the subject of great importance for safe and economical operation of such systems. 
This study compares the corrosion behaviour of austenitic stainless steel AISI 321 specimens with various surface pre-treatment. The same type of steel was used for construction of corrosion loop MatLoo. The effect of surface condition is valuable for the subsequent tests of materials tested in liquid lead but also for the optimum design of nuclear systems.

\section{EXPERIMENTAL}

\subsection{Material}

Austenitic stainless steel AISI 321 was used for the exposure in liquid lead. AISI 321 has excellent resistance to a wide variety of corrosive media, good resistance to oxidation up to $900{ }^{\circ} \mathrm{C}$, with temperature changes up to $800{ }^{\circ} \mathrm{C}$. The material is characterized by good ductility.

The nominal composition of AISI 321 (wt.\%) is Fe-Cr-17.16Ni-9.10Mn-1.63Si-0.44Cu-0.39Ti0.25Mo-0.24. Austenitic steel was produced by Hindustan Inox Ltd. The material was provided in a form of a bar of $12 \mathrm{~mm}$ diameter.

\subsection{Specimens}

The cylindrical specimens were fabricated by electrical discharged machining (EDM) in orientation of the bar longitudinal axis and finished by fine turning.

The test matrix used for the experiment in MatLoo loop was:

- $\quad$ As-received

- $\quad$ As-received + pre-oxidized

- $\quad$ Electro-polished

- $\quad$ Electro-polished + pre-oxidized

The surface of two specimens was electro-polished. Electro-polishing was done in a phosphoric acid type solution at $120{ }^{\circ} \mathrm{C}$. Applied current density was $300 \mathrm{~mA} / \mathrm{cm}^{2}$ during operation time of $10 \mathrm{~min}$. Another two specimens were not pre-treated. Two specimens, as-received specimen and electro-polished, were pre-oxidized in argon with $30-50 \mathrm{~Pa} \mathrm{O}_{2}$ at $450-500{ }^{\circ} \mathrm{C}$ for 14 days.

\subsection{Experimental procedure}

The specimens were exposed to the liquid lead at $480{ }^{\circ} \mathrm{C}$, flow velocity $3 \mathrm{~m} / \mathrm{s}$ and oxygen concentration $10^{-7} \mathrm{wt} . \%$ in corrosion loop MatLoo for $500 \mathrm{hr}$. The concentration of dissolved oxygen in liquid lead was controlled by mass exchange between free level of flowing metal and cover gas. Composition of cover gas was changed by mixing the $\mathrm{Ar} 6.0$ with $\mathrm{Ar}-10 \% \mathrm{O}_{2}$ or $\mathrm{Ar}-5 \% \mathrm{H}_{2}$ as needed. The oxygen concentration was continuously monitored by electrochemical oxygen sensors with $\mathrm{Bi} / \mathrm{Bi}_{2} \mathrm{O}_{3}$ reference electrode.

The Scanning Electron Microscope (SEM) with Energy Dispersive Spectroscopy (EDS) was used for pre-test and post-test examination of the surfaces and the cross sections of the specimens. Micro Vu Vertex 251HM was used for 3D optical measuring of dimensions of specimens.

\section{RESULTS}

The influence of the pre-oxidation procedure resulted in oxidation of the surface of the specimens. As-received specimen visually looked worse than electro-polished one (Figure 1). 


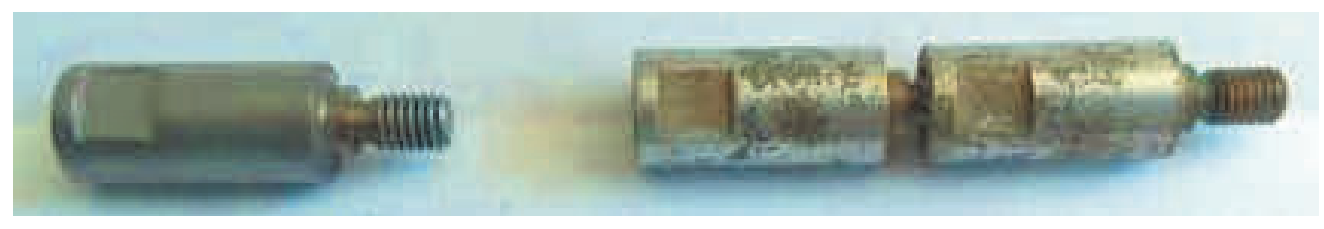

Figure 1 Specimen appearance after the pre-oxidation: electro-polished (left), as-received (right)

Figure 2 shows the surface of the all specimens before the exposure in the liquid lead. After the electro-polishing TiN/TiC particles become visible on the surface which could cause subsequent attack (Figure 2c). Observation of the electro-polished + pre-oxidized specimen surfaces showed compact oxide layer (Figure 2d). The as-received + pre-oxidized specimen showed the remains of non-protective heterogeneous oxide layer in the small non-continues islands (Figure $\mathbf{2 b}$ ), which appeared to be Cr-rich regions (Figure 3).

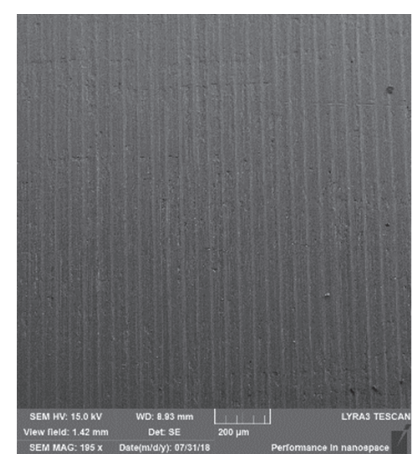

a)

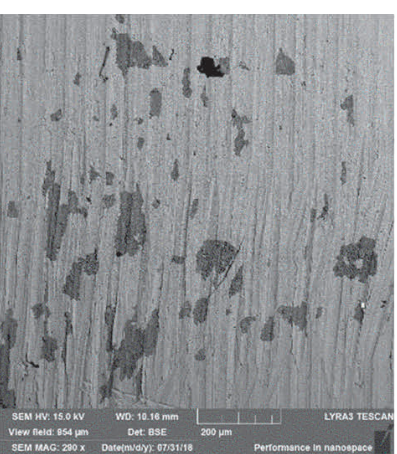

b)

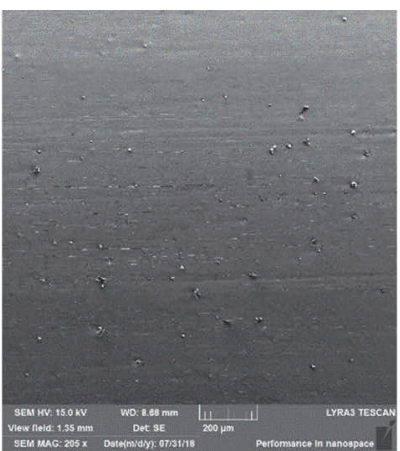

c)

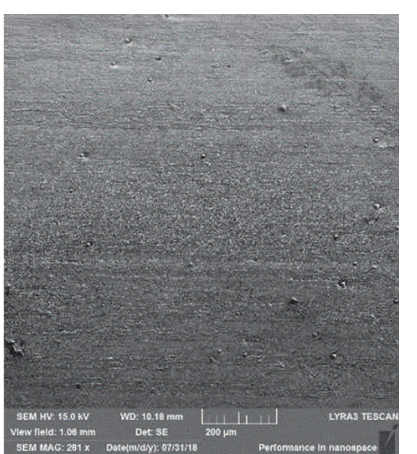

d)

Figure 2 Specimen surface before exposure in loop MatLoo for $500 \mathrm{hr}$ : a) as-received (SE),

b) as-received + pre-oxidized (BSE), c) electro-polished (SE), d) electro-polished + pre-oxidized (SE)
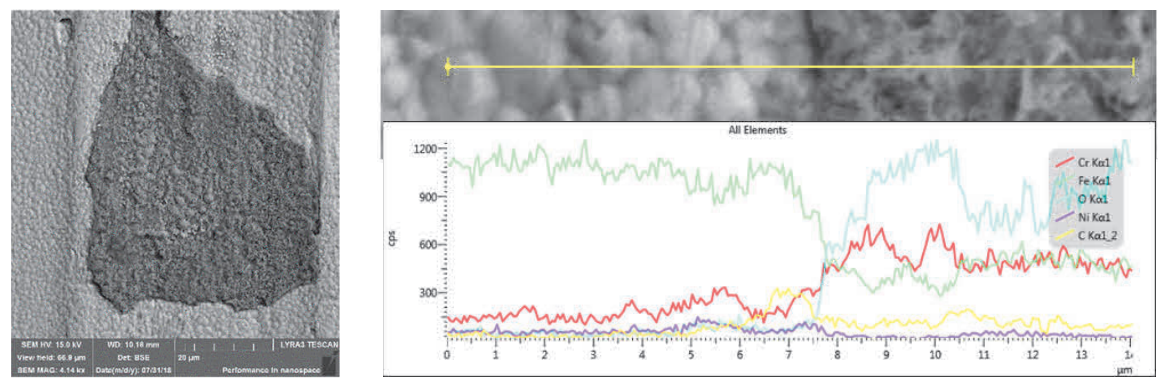

Figure 3 EDX pattern of the as-received + pre-oxidized specimen before exposure in liquid lead

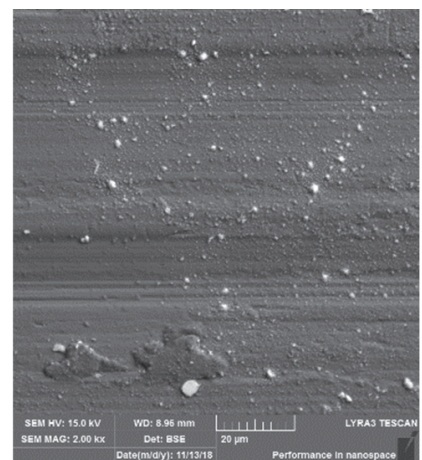

a)

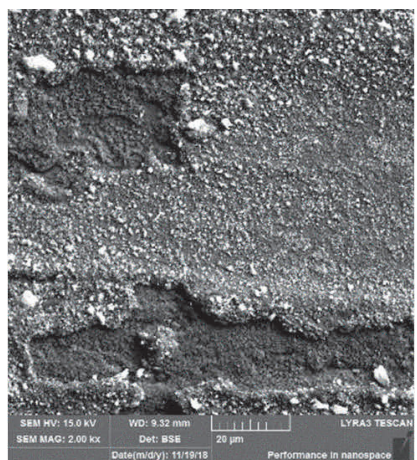

b)

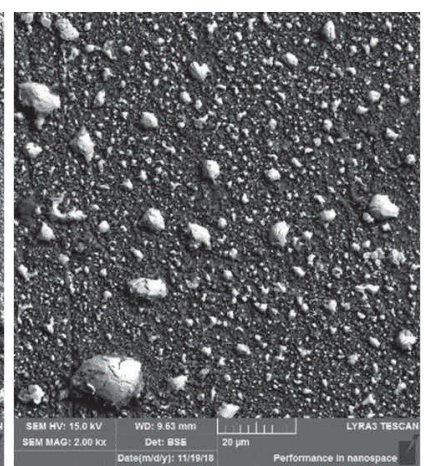

c)

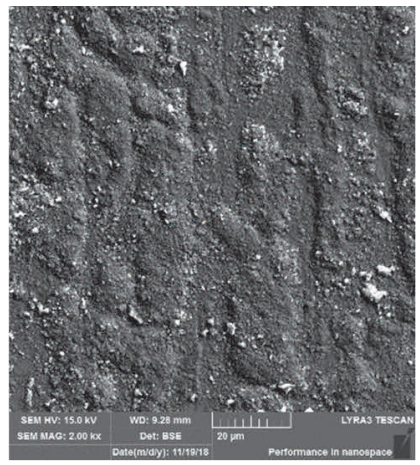

d)

Figure 4 Specimen surface after the $500 \mathrm{hr}$ exposure in the liquid lead a) as-received, b) as-received + pre-oxidized, c) electro-polished, d) electro-polished + pre-oxidized 
The SEM observation of the surface after the $500 \mathrm{hr}$ exposure in the liquid lead demonstrated significant differences in the behaviour and in the formation of thin oxide layers of the specimens. On the non-pre-oxidized as-received and electro-polished specimens surfaces were observed homogenous and compact layers of Fe-Cr-O. The oxide layer did not peel out in the specimens (Figures $4 a, c)$. The surface of the pre-oxidized specimens had a different structure developed from the pre-oxide layer. The as-received + pre-oxidized specimen formed a non-homogeneous and non-protective outer layer which was partially peeled out after the $500 \mathrm{hr}$ (Figure 4b). The electro-polished + pre-oxidized specimen formed a thick compact oxide (Figure 4d).
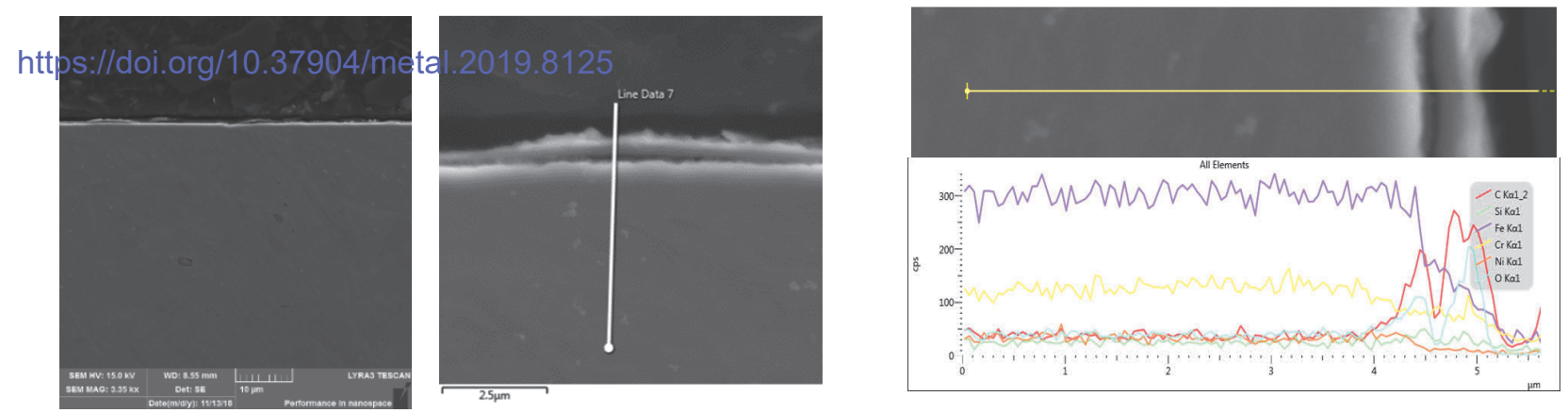

Figure 5 Cross section of the as-received specimen after the exposure in liquid lead

For the specimens exposed in liquid lead, a study of the cross-section was also carried out, in order to characterize the formation of the protective oxide layer. The cross-section of the as-received specimen (Figure 5) showed a thin compact oxide layer formed by Fe and Cr. From EDX observation the oxide layer was form the duplex oxide scale which is composed of two regions with different composition. Both layers were formed by $\mathrm{Fe}-\mathrm{Cr}-\mathrm{O}$, but the outer one had less $\mathrm{Fe}(\mathrm{Cr}-\mathrm{Fe}-\mathrm{O})$ and the inner one had less $\mathrm{Cr}(\mathrm{Fe}-\mathrm{Cr}-\mathrm{O})$.
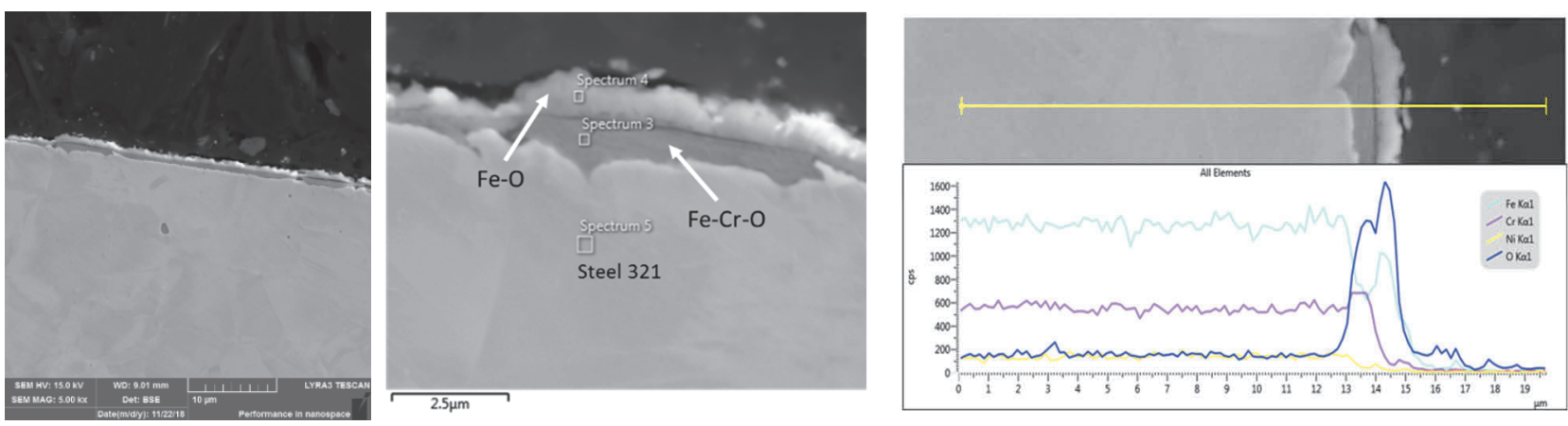

Figure 6 Cross section of the electro-polished specimen after the exposure in the liquid lead

On the electro-polished specimen the oxide layer was compact (Figure 6). The compact layer was stable and formed by the outer $\mathrm{Fe}-\mathrm{O}$ and the inner $\mathrm{Cr}-\mathrm{Fe}-\mathrm{O}$. Similar to the as-received specimen, the double layer was observed on electro-polished + pre-oxidized (Figure 7) and as-received + pre-oxidized (Figure 8) specimens. The same structure of the layer was observed on the electro-polished + pre-oxidized specimen. The appearance of the electro-polished and the electro-polished + pre-oxidized specimens were very similar, but the later one had the outer layer peeled out and damaged and in some place also the inner layer. Structure of the layers in the electro-polished + pre-oxidized specimen was uncoherent.

On electro-polished specimen cross sections a small cracks along grain boundaries were found. In these cracks the oxide layer formed preferentially in the exposure in the liquid lead. The cracks were larger in the electro-polished + pre-oxidized specimen in comparison to the electro-polished one. The cracks filled with oxide were observed over the entire surface. 

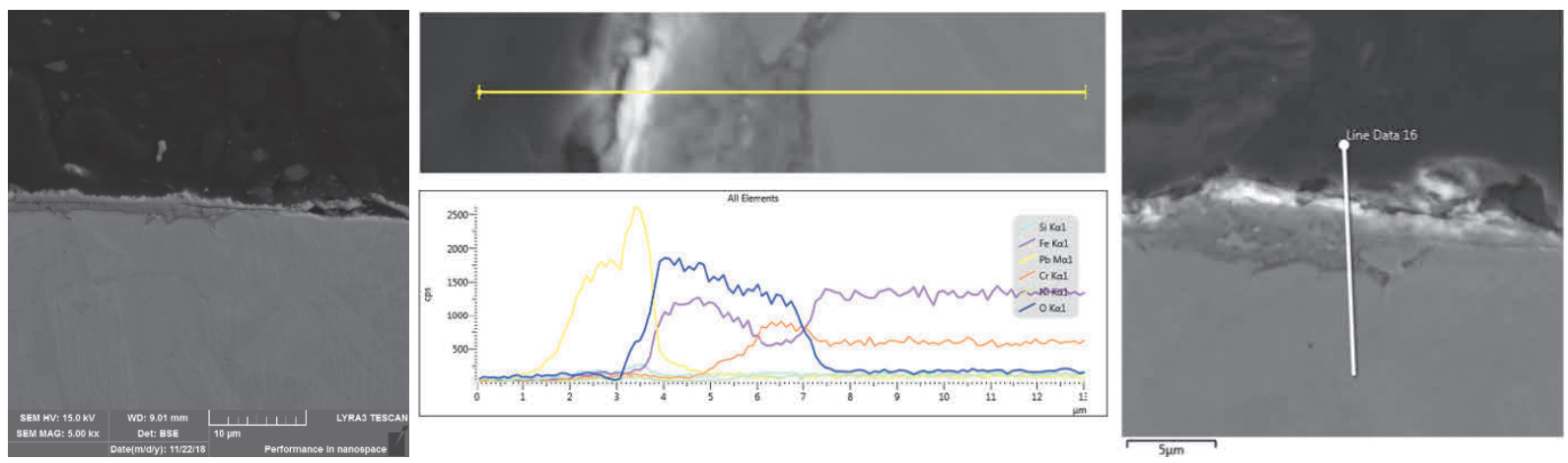

Figure 7 Cross section of the electro-polished + pre-oxidized specimen after the exposure in the liquid lead

The as-received + pre-oxidized (Figure 8) looked the worst in the comparison with the all observed specimens. The layer was much disrupted, damaged and non-adherent. The created oxide layer was unstable over the entire surface. Undisrupted layer was observed only exceptionally.
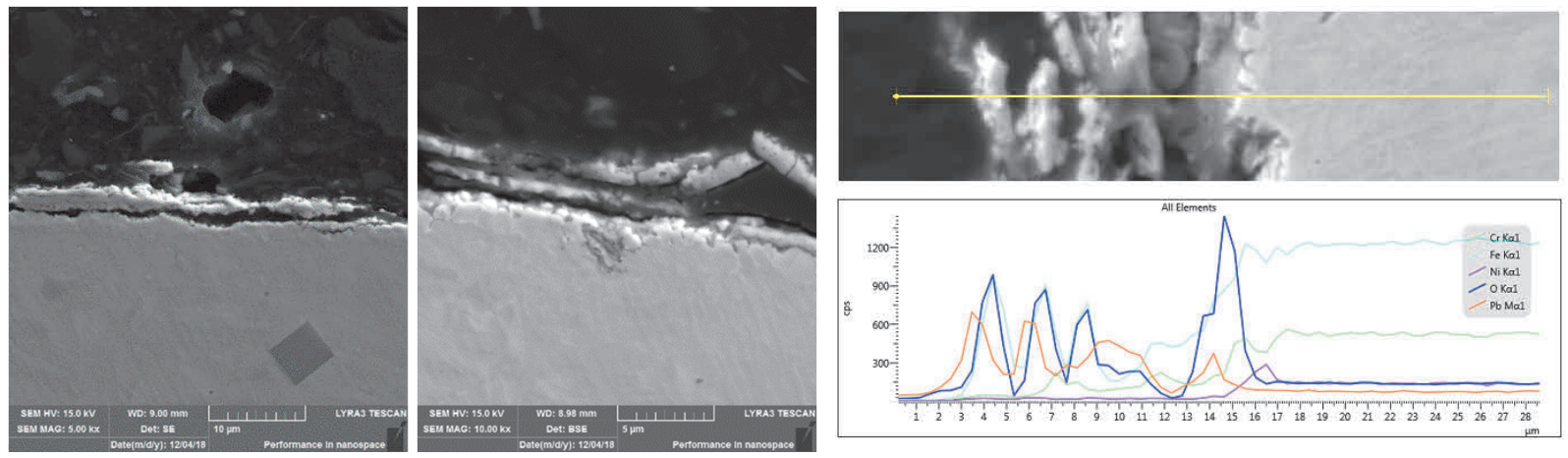

Figure 8 Cross section of as-received + pre-oxidized specimen after the exposure in the liquid lead

\section{DISCUSSION}

Compared to corrosion behaviour of steels, investigations on the behaviour of surface pre-treatment of specimens in oxygen-containing lead alloys ( $\mathrm{Pb}$ or LBE) are few in the technical literature. After exposure to static LBE in the range of temperature at $450-550^{\circ} \mathrm{C}$, specimens showed predominantly oxidation (bi-oxide layer scale) $[9,10]$. At a temperature of $480^{\circ} \mathrm{C}$ and oxygen concentration of $10^{-7} \mathrm{wt} . \%$ which might correspond to normal operating temperatures of lead cooled ADS systems, the oxygen control becomes important for the use of AISI 321. Previous investigations have shown that the austenitic steel is compatible with liquid lead under precisely defined conditions, so that indicate the need for the precise oxygen control, i.e., prevention of local oxygen depletion in the liquid metal [11].

The SEM observation demonstrated significant differences in the behaviour and in the formation of thin oxide layers of the specimens. The results of surface observation before exposure showed that the pre-oxidation is not improving the performance in the liquid lead. Specimens without the pre-oxidation process showed better formed oxide layers. After the exposure in the liquid lead the best performance showed that specimen left in the as-received surface condition. The oxide layer formed on the as-received specimen was thin and adherent, thus apparently protective. On the other hand, the pre-oxidized specimen formed non-homogeneous and non-protective oxide layer and the electro-polished specimens showed vulnerability to an intergranular corrosion attack. It's not clear if this damage is caused by polished surface or was caused by electro polishing procedure it-self. It is important to point out the difference in behaviour between the pre-oxidation specimens and non-pre-oxidation specimens. The pre-oxidation showed to be very undesirable pre-treatment of the steel. However, in any of the pre-treatments dissolution attack was not been observed. 


\section{CONCLUSION}

- $\quad$ None of the applied pre-treatments did improve the AISI 321 performance in the liquid lead.

- $\quad$ The oxide layer of the as-received specimen was homogeneous and adherent.

- $\quad$ The pre-oxidation appeared to be undesirable process.

- After $500 \mathrm{hr}$ in the liquid lead at $480{ }^{\circ} \mathrm{C}$ and oxygen concentration of $10^{-7}$ wt. $\%$ - no dissolution attack was observed.

\section{ACKNOWLEDGEMENTS}

The presented work was carried out in the frame of the H2020-GEMMA project, GA $N^{\circ}: 755269$, IPNOP 18D0013 and financially supported by the Ministry of Education, Youth and Sport Czech Republic project LQ1603 Research for SUSEN. This work has been realized within the SUSEN Project (established in the framework of the European Regional Development Fund (ERDF) in project CZ.1.05/2.1.00/03.0108 and of the European Structural and Investment Funds (ESIF) in the project CZ.02.1.01/0.0/0.0/15_008/0000293).

\section{REFERENCES}

[1] SUBBOtIN, V.I., ARNOL'DOV, M. N., KOZLOV, F. A. and SHIMKEVICH, A. L. Liquid-Metal Coolants for Nuclear Power. Atomic Energy. 2002. vol. 92, pp. 29-40.

[2] FÉRON, D. In: Nuclear corrosion science and engineering. Cambridge: Woodhead Publishing. 2012, Part III: Liquid metal corrosion in nuclear reactor and accelerator driven systems, chapter 10, pp. 301-326.

[3] ZHANG, J. A review of steel corrosion by liquid lead and lead-bismuth. Corrosion Science. 2009. vol. 51, pp. 1207-1227.

[4] SCHROER, C. and KONYS. Physical chemistry of corrosion and oxygen control in liquid lead and lead-bismuth eutectic. Wissenschaftliche Berichte FZKA 7364. Forschungszentrum Karlsruhe in der Helmholtz-Gemeinschaft. 2007. p. 17.

[5] GROMOV, B.F., TOSHINSKY, G.I. and CHEKUNOV, V.V. Designing the Reactor Installation with Lead-Bismuth Coolant for Nuclear Submarines. The Brief History. Summarized Operation Results. In Heavy liquid coolants in nuclear Technology. Obninsk: V. S. Stepanov Gidro press, 1999, 167-173.

[6] IAEA: Liquid Metal Cooled Reactors: Experience in Design and Operation. TECDOC-1569. 2007.

[7] REISTAD, O. and ØLGAARD, P.L. Russian Nuclear Power Plants for Marine Applications. Roskilde: NKS138,2006, p. 95.

[8] SMITH, C.F. et. al.: SSTAR: The US lead-cooled fast reactor (LFR). Journal of Nuclear Materials. 2008. vol. 376, pp. 255-259.

[9] KURATA, Y., FUTAKAWA, M. and SAITO, S. Comparison of the corrosion behaviour of austenitic and ferritic/martensitic steels exposed to static liquid $\mathrm{Pb}-\mathrm{Bi}$ at 450 and $550^{\circ} \mathrm{C}$. Journal of Nuclear Materials. 2005. vol. 343, pp. 333-340.

[10] KURATA, Y., FUTAKAWA, M. and SAITO S. Corrosion behaviour of steels in liquid lead-bismuth with low oxygen concentrations. Journal of Nuclear Materials. 2008. vol. 373, pp. 164-178.

[11] SOLER, L., MARTIN, F.J., HERNANDEZ, F. GOMEZ-BRICERIO, D. Corrosion of stainless steels in lead-bismuth eutectic up to $600{ }^{\circ} \mathrm{C}$. Journal of Nuclear Materials. 2004. vol. 335, pp. 174-179. 